\title{
QUEM CUIDARÁ DE NÓS EM 2030?: PROSPECÇÃO E CONSENSO NA REGIÃO METROPOLITANA DE SÃO PAULO
}

\author{
Bernadete de Oliveira ${ }^{1}$ \\ Maria Helena Villas Bôas Concone ${ }^{2}$ \\ Flamínia Manzano Moreira Lodovici \\ Ruth Gelehrter da Costa Lopes ${ }^{4}$ \\ Beltrina Côrte ${ }^{5}$
}

\begin{abstract}
1 Graduada em Fisioterapia. Doutora em Ciências Sociais: Antropologia. Docente em Cursos de Formação de Cuidadores de Idosos; Cursos lato sensu de Gerontologia (COGEAE/PUC-SP) e de Psicogerontologia (UNIP-Vergueiro); Cursos de Gerenciamento de Cuidados ao Idoso (EMS-Cidade de São Paulo). E-mail: bbell_o@yahoo.com.br

2 Graduada em Antropologia. Doutora em Ciências Sociais: Antropologia. Professora Titular da Pontifícia Universidade Católica de São Paulo (PUC-SP), vinculada ao Departamento de Ciências Sociais, Programa de Estudos Pós-Graduados em Ciências Sociais: Antropologia/FCS e ao Programa de Estudos Pós-Graduados em Gerontologia/FACHS/PUC-SP. E-mail: mhconcone@yahoo.com.br

3 Graduada em Letras. Doutora em Linguística. Professora Assistente-Doutor da PUC-SP, vinculada ao Departamento de Linguística/FAFICLA/PUC-SP e ao Programa de Estudos Pós-Graduados em Gerontologia/FACHS/PUC-SP. E-mail: flodovici@pucsp.br

4 Graduada em Psicologia. Doutora em Saúde Pública. Professora Associada da PUC-SP, vinculada ao Departamento de Psicologia/FACHS/PUC-SP e ao Programa de Estudos Pós-Graduados em Gerontologia/FACHS/PUC-SP. E-mail: ruthgclopes@gmail.com

5 Graduada em Jornalismo. Pós-Doutorado em Ciências da Comunicação pela Universidade de São Paulo/USP-SP, vinculada ao Programa de Estudos Pós-Graduados em Gerontologia/FACHS/ PUC-SP. E-mail: beltrina@pucsp.br
\end{abstract}


resumo

Este é um estudo norteado pela questão "Quem cuidará de nós em 2030?", desenvolvido na Região Metropolitana de São Paulo, ancorado nas Políticas Públicas Brasileiras de Atenção à Saúde do Idoso. Ele investiga as opiniões de representantes de Conselhos Municipais (de Saúde e do Idoso) a respeito do tema-questão. A perspectiva é antropológica, com abordagem interdisciplinar na coleta de dados e na sua interpretação. Os resultados da prospecção e consenso foram: (I) é desnecessário instituir um hospital de retaguarda para o idoso se recuperar e voltar para casa com independência e autonomia; (II) é necessário capacitar todos os profissionais da rede pública; e (III) reconhece-se o aumento da demanda de cuidados na velhice. Os Conselhos Municipais podem vir a ser um poderoso instrumento de participação social, de consecução da esfera pública e das políticas que devem atender de modo satisfatório às demandas do devir da velhice.

palavras - chave

Método Prospectivo. Sistema Público de Saúde Brasileiro. Pessoas ldosas.

A população mundial cresce a uma velocidade preocupante, chegando a 7 bilhões em 2011. Estima-se que ultrapasse 9 bilhões em 2050 (OMS, 2011). No mundo, 893 milhões de pessoas têm 60 ou mais anos ( 1 em cada 8 pessoas com idade $\geq 60$ anos). Até a metade deste século, prevê-se o triplo: 2,4 bilhões ( 1 em cada 4 , com idade $\geq 60$ anos). A expectativa de vida média é de 68 anos, quando era de apenas 48 em 1950 (OMS, 2011) ${ }^{6}$.

O Brasil também envelhece: a par da diminuição da fecundidade, a expectativa de vida ao nascer (1960-2010) aumentou de 41 para 73 anos de idade, com os idosos passando de 3 para 21,7 milhões (1960-2010) (IBGE, 2010). Estimativas referentes à projeção em 2030, do Pico Demográfico da População Brasileira, postulam 206,8 milhões de habitantes, sendo 28,9 de idosos,

6 Fonte: BBC Brasil. Relatório do Fundo de População das Nações (UNFPA), 2011. Organização das Nações Unidas. Situação da População Mundial 2011. Disponível em: <http://www.bbc.co.uk/ portuguese/noticias/2011/10/111025_onu_populacao_jovens_malb.shtml>. Acesso: 1 nov. 2011. 
14\% da população total (FIOCRUZ, 2012). Note-se que a França levou mais de um século para seus idosos atingirem 14\%, os Estados Unidos da América, 70 anos, e a Espanha, 40 (DANTAS, 2011).

O Brasil, país de grande extensão territorial, conta com mais de 185 milhões de habitantes em diferentes regiões com diversas condições econômicas, demográficas, geográficas e climáticas, o que determina condições de vida distintas e demandas desiguais, com diferenças de gênero, etnia, classe social e idade (IBGE, 2010).

Imaginar um modelo de saúde que atenda a todo o país parece inexequível, embora ele já funcione, como instituído pela Constituição Brasileira: o Sistema Único de Saúde (SUS), por meio do qual a população brasileira, na sua totalidade, deve ter garantidas ações de promoção da saúde, prevenção de doenças, cura e reabilitação (BRASIL, 1988).

A Atenção à Saúde do Idoso já é em si tema relevante pela contribuição aos conhecimentos sobre o SUS, dado o seu caráter universal garantido pelos princípios da Constituição (BRASIL, 1988). Constitui em um grande desafio à gestão pública, hoje e em futuro próximo, especialmente quanto à definição do atendimento ao idoso dependente ou àquele que reside só ou sem vínculo familiar.

O envelhecimento populacional - processo natural do ciclo da vida ou fenômeno coletivo - é permeado de complexos aspectos que demandam a intervenção do Estado sob olhar da família e da sociedade civil. O mecanismo mais viável para atender a essas demandas é a elaboração/implementação de ações/serviços destinados a concretizar direitos ao segmento idoso, concretizando o exercício da cidadania, esta implicando o engajamento em questões sociais, na busca de soluções, benefícios e igualdade a todos. $\mathrm{O}$ advento do Estatuto do Idoso (01/10/2003, Lei 10.741) é reconhecido pelas comunidades como mecanismo de regulamentação de direitos específicos, como a prioridade de atendimento ao idoso. Destacam-se os papéis da família, da sociedade civil e do Poder Público ao assegurar os direitos do idoso à saúde, alimentação, cultura, lazer, trabalho, liberdade, respeito e convivência familiar (BRASIL, 2003).

O SUS foi afirmado na Constituição (BRASIL, 1988), fundado na premissa da saúde como direito de todos e dever do Estado, e nos princípios e diretrizes da universalidade, equidade, integralidade, descentralização e controle social. Esses mecanismos contribuíram na difusão de ações, serviços e informações para prevenir doenças e promover a saúde da população, o que demonstra a força do ideário e do conjunto de atores (cidadãos) e instituições, construtores do SUS, tornando-o verdadeiro patrimônio público que, como tal, deve ser bem cuidado. 
O processo de implantação do SUS exigiu a construção de sofisticada engenharia institucional, com gestão que pudesse dar conta da complexidade da produção de saúde no País. A participação da comunidade, por meio de Conselhos, formulação de estratégias e controle da execução da política de saúde, inclusive nos aspectos econômicos e financeiros de serviços/ações, fazem parte desta proposta assegurada pela Constituição e Leis Orgânicas da Saúde 8.080/90 e 8.142/90 (BRASIL, 2002).

Os Conselhos Municipais de Saúde, em geral, têm composição tripartite, com representantes da Secretaria Municipal de Saúde, subdivididos em segmento gestor (diretores de Unidades de Saúde) e de profissionais (trabalhadores) de saúde (25\%), de prestadores de serviço (25\%) e usuários (50\%). Os Conselhos Municipais do Idoso, que representam as esferas do Governo (50\%) e da sociedade civil (50\%), atuam no processo de cumprimento de Políticas Públicas, sobretudo da Política Nacional de Saúde da Pessoa Idosa (PNSPI), contribuindo, ainda, para estabelecer diretrizes que norteiam a definição ou a redefinição dos programas, projetos e atividades na atenção integral à população idosa (BRASIL, 2006). É função dos membros desses Conselhos orientar a população idosa residente nos municípios sobre direitos nas áreas de habitação, saúde, transporte, trabalho, assistência social, segurança, lazer, educação e cultura (BRASIL, 1988).

O presente estudo foi realizado com sujeitos (conselheiros) que representam esses órgãos permanentes e deliberativos na Região Metropolitana de São Paulo (RMSP) (janeiro de 2011-dezembro de 2012), com grupos de representantes dos Conselhos Municipais de Saúde e do Idoso. A fim de prover perspectivas consensuais à pergunta "Quem cuidará de nós em 2030?", referencia-se, a seguir, o caminho metodológico percorrido.

\section{Métodos}

O modelo da pesquisa, que se inscreveu na vertente empírica do trabalho de campo, subdividiu-se em três fases, sendo uma presencial e duas virtuais. Buscou-se obter opiniões dos grupos de representantes (singularidades e totalidades, mais propriamente) sobre questões antes acordadas, em investigação quantitativa, qualitativa e prospectiva, a respeito do entendimento e a interpretação da temática em foco, bem como o que preveem para o futuro as diretrizes das políticas públicas de Atenção à Saúde do Idoso, descritas em documentos oficiais. Ao comportar a análise interpretativa à procura de significados, o modelo deste estudo buscou depreender "um padrão de significados 
transmitido historicamente", cujas "concepções herdadas" expressam "formas simbólicas por meio das quais os homens comunicam, perpetuam e desenvolvem seu conhecimento e suas atividades em relação à vida" (GEERTZ, 1973, p. 66).

À tarefa, "o entendimento do entendimento" denominou-se hermenêutica ou "a teoria e a metodologia da interpretação"; em certo sentido, explicitada, principalmente, ao lhe associar a palavra "cultural" (GEERTZ, 1997, p. 11). Tal indicação fez-se valer como ferramenta eficaz para explorar, nos Conselhos Municipais, o conflituoso âmbito das políticas públicas, especificamente as voltadas à Atenção à Saúde do Idoso no Brasil, que se pautam em saber interdisciplinar, mescla de campos de conhecimento muito singular. Sociologia, economia, política, filosofia, biologia, psicologia e linguística, saberes diversos sobre o tratamento ao idoso foram consultados neste estudo, buscando-se conciliar opiniões que, muitas vezes, pareciam inconciliáveis. Não abandonados os referenciais, estes foram, ao contrário, usados a favor de um compromisso com o outro e a responsabilidade pelo bem comum da comunidade. Esta é uma visão de mundo que subsome aspectos cognitivos (memória, raciocínio, atenção, percepção e representação de conhecimento) e existenciais elaborados, no caso deste estudo, no conteúdo dos discursos dos conselheiros. Geertz (1973, p. 142-143) diz que visão de mundo "é o quadro elaborado de uma dada realidade sociocultural ('das coisas como elas são na realidade')", ou, em outras palavras, "é a concepção aí elaborada, de natureza, das pessoas e da sociedade." (CONCONE, 2003, p. 52).

\subsection{População estudada}

O estudo de campo, regido por critérios de inclusão/exclusão, evoluiu, na sua aplicação nos 39 municípios da RMSP, com algum decréscimo do número de participantes por desistência ou não localização durante o processo: dos 109 sujeitos participantes da primeira fase, $68(62,4 \%)$ mantiveram-se na segunda e, destes, 51 (75\%) participaram da terceira.

\subsection{Primeira fase: entrevista presencial gravada}

A este empírico fundado na técnica de gravação de voz, antecedeu-se o pré-teste (refinamento) dos instrumentos de pesquisa: a submissão do questionário misto e do Termo de Consentimento Livre e Esclarecido (TCLE), em março-junho de 2011, a três etapas pré-testes, com dez "juízes especialistas" 
na área da Saúde do Idoso, e bacharelados/mestres em Gerontologia, de áreas diversas das Ciências da Saúde e Humanas. Após, mais duas etapas de pré-testes com outros cinco "juízes leigos" (não peritos da área técnica de saúde). A contribuição maior dos pré-testes foi propiciar a familiaridade (1) com os instrumentos de pesquisa e (2) com as adversidades do trabalho de campo propriamente dito, destacando-se a especial postura da desenvolvida "escuta sensível" - viabilizando-se o elo sujeito-projeto (fundamental na retomada de contato pró-adesão às fases subsequentes).

Ao término da etapa 1, as transcrições das entrevistas gravadas tornaram-se matéria-prima para a consecução de formulários e instrumentos de pesquisa do Delphi descrito a seguir.

\section{Método Delphi Eletrônico}

Nas fases 2 e 3 do estudo, o trabalho de campo, com utilização da plataforma web na coleta de dados, consistiu na consulta de opiniões de um "grupo de especialistas" sobre eventos futuros e na consolidação do entendimento do grupo sobre a temática em foco - sendo o formulário repassado continuadas vezes até obtido, na convergência de respostas, o previsto consenso de opiniões: "Pressupõe-se que o julgamento coletivo, ao ser organizado, é melhor do que a opinião de um só indivíduo" (WRIGHT; GIOVINAZZO, 2000, p. 54).

Seguindo a aplicação do método, para manter o vínculo sujeitos-tema do projeto, o retorno aos sujeitos foi enunciado, nas etapas 1 e 2, por meio de estratégias locais de comunicação: palestras, entrevistas a jornais virtuais e impressos. O processo interativo possibilitou dar "retorno" à pergunta feita e manter o "elo", participantes-pesquisa, no decurso do estudo. Note-se que "a pesquisa qualitativa, exatamente porque é um exercício político, porque trabalha com os significados de vivências, precisa ser devolvida aos sujeitos que dela participaram" (MARTINELLI, 1999, p. 26).

Uma característica peculiar do trabalho foi a consulta não limitada a "especialistas", técnicos da saúde investidos no papel de conselheiros. Buscou-se a opinião qualificada de membros da sociedade civil, igualmente investidos na função pública de conselheiros que, embora "leigos", a seu modo, puderam qualificar-se como "especialistas" por participarem democraticamente da definição dos serviços públicos de saúde nos municípios onde residiam. Apresenta-se a seguir cada passo da sequência de execução do Método Delphi eletrônico. 
No período de 2 a 17 de agosto de 2012 (15 dias), ocorreu o Ciclo I do Delphi na RMSP. Nesse ciclo, os 109 (100\%) sujeitos em primeira etapa foram convidados, via eletrônica, para sua resposta ao formulário disponibilizado on-line na plataforma web, em três formatos diferentes, um para cada grupo de representantes de Conselho. Os sujeitos também foram contatados por telefone para esclarecimentos sobre a pesquisa e a importância de eles enviarem as respostas via Internet. A meta mínima de adesão de $50 \%$ de cada grupo participante foi bem sucedida, com $62 \%(n=68)$ do total de sujeitos-respondentes.

\subsection{Terceira fase: ciclo II do Delphi}

Do total de 109 sujeitos, 68 foram convidados para participar do Ciclo II (excluídos os 32 não participantes do Ciclo I); destes, 51 (75\%) responderam ao formulário do Ciclo II, de 18/08 a 27/09/2012. Monitorada cada participação (e armazenada no repositório digital web), constatou-se que a não adesão distanciava o consenso de opiniões. Reenviou-se, então, o formulário a todos os sujeitos não respondentes; pouco retorno se obteve, porém, mesmo reiterado o valor de participação na pesquisa, via ligações telefônicas e/ou Internet.

Perfazer o Delphi na RMSP exigiu 54 dias, dois ciclos completos. A literatura evidencia: em dois ciclos, é "possível chegar a um consenso na maioria das questões discutidas", e que mais de dois tornariam a pesquisa "desinteressante para os participantes" (GIOVINAZZO, 2001, p. 10). Neste estudo, optou-se pela finalização no Ciclo II, atingido o valor acima de $60 \%$ na tabulação estatística das respostas às questões - uma convergência satisfatória.

\subsection{Avanços e limitações do Delphi}

Fator restritivo à aplicação do Delphi, a demora na resposta aos formulários, mormente ao segundo, indiciou dificuldades na adesão de grupos. Observou-se que o curto espaço de tempo entre os ciclos interativos pouco repercutiu na motivação/adesão dos participantes, mesmo disponibilizando o formulário on-line 24 horas, possibilitando-lhes preenchimento em qualquer local. Embora a descrição do Delphi não requisite um número preestabelecido de componentes na formação de um grupo, a redução de engajamento dos representantes no processo, somada à excessiva demora na realização dos ciclos completos, implicou, neste estudo, disponibilidade extra de tempo e infraestrutura para 
o custoso reenvio de formulários via eletrônica e incontáveis ligações telefônicas. Em contrapartida, foi um método particularmente válido por permitir abarcar vasta área territorial, evitando novas despesas de idas a campo. $\mathrm{O}$ grande número de participantes e a diversidade de localidades investigadas na primeira fase foram relevantes, ao induzirem à criatividade e conferirem credibilidade ao estudo. Relativamente às demais restrições, as dificuldades enfrentadas foram as inerentes à técnica. Procederam-se a formatação da plataforma web, a elaboração de formulários, a sistematização, a tabulação e a análise das respostas, etapas que, para avançarem em sua legitimação, exigiram dos pesquisadores além de conhecimento aprofundado de método, ética, imparcialidade, organização e criatividade.

\subsection{Modulando os dados}

A análise dos resultados inicia-se aqui com a descrição dos dados quantitativos quanto a marcadores socioeconômicos e profissionais dos entrevistados; e, posteriormente, aos resultados qualitativos oriundos dos discursos dos sujeitos, conforme a abordagem prospectiva (HELMER, 1977), soma-se o referencial teórico interpretativo (GEERTZ, 1973; 1997).

\subsection{Primeira fase: marcadores socioeconômicos e profissionais}

Na primeira parte de análise dos resultados, apresenta-se o tratamento quantitativo; inicia-se caracterizando a representatividade dos Conselhos Municipais da RMSP; em seguida, a descrição do perfil dos conselheiros seguindo os marcadores sociológicos clássicos do conjunto de sujeitos.

Representatividade dos grupos: enquanto todos os municípios participaram com representantes da Secretaria de Saúde $(\mathrm{n}=39 ; 36 \%)$, seguidos da participação de representantes dos usuários ( $n=37 ; 34 \%)$, quase todos eles dispunham de CMI ( $n=33 ; 30 \%)$, correspondentes à participação dos representantes dos idosos, a 84,6\% da região, dada a desativação do CMI em 6 municípios (15,4\% da região). 
Categorias dos sujeitos: segundo diretrizes oficiais que estabelecem as categorias que compõem o CMS e o CMI, os conselheiros foram identificados respectivamente como segmentos gestor, trabalhador e usuário, do governo e da sociedade civil, ou seja: segmento usuário com maior destaque ( $\mathrm{n}=37$; $34 \%$ ) do que o gestor $(\mathrm{n}=27 ; 24,8 \%$ ) e o trabalhador $(\mathrm{n}=12 ; 11 \%)$, e maior número de participantes do governo $(\mathrm{n}=18 ; 16,5 \%)$ do que da soiedade civil $(\mathrm{n}=15 ; 13,8 \%)$. Os sujeitos relataram estar em média há 2 anos e 8 meses $( \pm 3,2$ anos) representando o município como conselheiros (amplitude: tempo mínimo um mês e máximo 18 anos).

Composições etárias: a distribuição proporcional dos sujeitos segundo faixa etária mostra concentração expressiva dos representantes dos Conselhos na de 50 anos e mais de idade ( $\mathrm{n}=67 ; 61,5 \%)$. Em um extremo, observou-se apenas $3(2,8 \%)$ entre 20-29 anos, 2 representantes do CMS e um do CMI (segmentos trabalhador, gestor e governo). No outro extremo, foram $9(8,2 \%)$ na faixa de 70 anos ou mais, sendo 4 do segmento usuário, 4 da sociedade civil e um do governo.

Distribuição por sexo: entre os conselheiros participantes, há predominância $(n=57,52,3 \%)$ do feminino. Homens representam 47,5\% ( $n=52)$ dos respondentes. As diferenças nessa proporção evidenciam-se quando a informação é desagregada por sexo: entre homens, as maiores proporções de ocupação foram situadas nos Conselhos de saúde, em que 23 (21,1\%) são membros do segmento usuário, 14 (12,8\%) do segmento gestor e 7 (6,4\%) do segmento trabalhador. Entre as mulheres, as proporções representativas, equilibradas entre os dois Conselhos são as mais elevadas ( $n=14 ; 12,8 \%$ ), pertencentes à esfera do governo e ao segmento usuário, seguidas pelas do segmento gestor $(n=13 ; 11,9 \%)$ e sociedade civil $(n=11 ; 10,1 \%)$.

Nacionalidade/naturalidade: a distribuição percentual e número total da categoria de sujeitos, por nacionalidade/naturalidade, mostra a pequena proporção de conselheiros estrangeiros $(n=5 ; 4,6 \%)$ em relação a brasileiros $(\mathrm{n}=104 ; 62,4 \%)$. Destes, 21 (19,3\%) nasceram na cidade onde moram; é expressiva ( $\mathrm{n}=68 ; 82,6 \%)$ a proporção de paulistas (natos no estado de São Paulo) em relação aos natos em regiões outras do país $(n=36 ; 33 \%)$.

Identificação do estado civil: ao comparar a proporção de conselheiros segundo o estado civil, evidencia-se que 70 (62,2\%) são casados ou em união estável. Saliente-se que as proporções são fortemente afetadas pela distribuição por sexo; no grupo dos casados, homens predominam ( $\mathrm{n}=40 ; 36,7 \%)$; a viuvez, vista apenas entre mulheres, foi o estado civil menos relatado $(n=8 ; 7,3 \%)$. 
Grau de escolaridade: outra variável, os anos de estudo. Em média, cada conselheiro tem 13,3 anos $( \pm 4,5)$, o que revela média de escolaridade superior à nacional, sugerindo a obtenção do ensino médio pela maioria.7 A média de escolaridade do brasileiro com 25 anos ou mais é de 7,1 anos de estudo, escolaridade anterior à conclusão do ensino fundamental (IPEA, 2012), o qual, incompleto ou completo, predomina entre homens $(n=12 ; 11 \%)$, enquanto entre mulheres, nível superior completo, $(\mathrm{n}=35 ; 32,1 \%)$.

Formação educacional e profissional: a maioria dos sujeitos graduados $(\mathrm{n}=36$; 33,0\%) é oriunda da área de Humanas: Administração ( $n=8 ; 7,3 \%)$, Ciências Econômicas ( $n=1 ; 0,9 \%)$, Ciências Sociais $(n=3 ; 2,8 \%)$, Direito $(n=3 ; 2,8 \%)$, Geografia ( $n=1 ; 0,9 \%)$, História $(n=2 ; 1,8 \%)$, Pedagogia $(n=4 ; 3,7 \%)$, Psicologia $(n=3 ; 2,8 \%)$ e Serviço Social $(n=12 ; 11 \%)$. Uma proporção expressiva declarou ter graduação em Ciências Biológicas ( $n=20 ; 18,3 \%)$; Ciências Biomédicas $(n=1 ; 0,9 \%)$, Educação Física $(n=2 ; 1,8 \%)$, Enfermagem $(n=9 ; 8,3 \%)$, Farmácia-Bioquímica ( $n=2 ; 1,8 \%)$, Medicina $(n=4 ; 3,7 \%)$ e Odontologia $(n=3 ; 2,8 \%)$. Na área de Exatas, tem-se um (0,9\%) graduado em Matemática.8 Sete conselheiros $(6,4 \%)$ têm formação técnica; 35 (32\%) nenhuma formação profissional; e 2 $(1,8 \%)$ nada responderam.

Fonte de conhecimento na área de Geriatria e/ou Gerontologia: a maior fonte de conhecimento dos conselheiros nessa área advém da participação em eventos ( $n=33 ; 30,3 \%$ ), seguido do curso de graduação universitária ou trabalho há mais de quatro anos na área (ambos com $n=22 ; 20,2 \%)$; para pequena parcela, a pós-graduação foi a fonte desse conhecimento $(n=4 ; 3,7 \%)$. Ao contrário do que se esperava, $51(46,8 \%)$ sujeitos negaram ter algum conhecimento na área. Mas, desse total, 16 (31,4\%) residiam com algum familiar idoso e os demais (35; 68,6\%), embora tivessem algum idoso na família, não moravam junto; por vezes, tais conhecimentos eram advindos do convívio próximo ou distante com familiares idosos.

Renda familiar: note-se que apenas os sujeitos pertencentes ao segmento gestor têm rendas na faixa mais alta, acima de dez salários-mínimos. Em contrapartida, dentro do grupo de usuários, estes possuem entre dois e quatro salários. Conselheiros que representam os usuários e os da sociedade civil apresentam idêntica diversidade de faixas de renda; somente trabalhadores

\footnotetext{
7 Esse dado é, no entanto, afetado pelos extremos: mínimo de 2 anos de estudo e máximo de 21.

8 A classificação de formação educacional e profissional neste estudo é a disponibilizada no Guia de Profissões da Universidade Estadual Paulista (Unesp). Disponível em: <http://www.vunesp.com. br/guia2013/unesp.html> Acesso em: 26 abr. 2013.
} 
não se inserem na faixa de oito a dez salários. ${ }^{9}$ Verificou-se, ainda, que a renda familiar mensal média dos conselheiros gira em torno de $\mathrm{R} \$ 5.050,00$, valor superior à renda média das famílias brasileiras. De acordo com a Pesquisa de Orçamentos Familiares (POF), entre os meses de maio de 2008-2009, cuja amostra incluiu 60 mil domicílios urbanos e rurais, a família brasileira teve rendimento médio de $\mathrm{R} \$ 2.763,47$ (FIOCRUZ, 2012).

\subsection{Terceira fase: abordagem prospectiva}

Na segunda parte da análise dos resultados, buscou-se explicitar as respostas alternativas a: (1) o entendimento prospectivo de diretrizes e responsabilidades (iniciativas e condutas); (2) os condicionantes sociais que envolvem o "discurso social local" relativo às políticas sociais dirigidas ao futuro da população idosa; (3) o contraponto de tais políticas sociais diante da perspectiva prospectiva da visão dos sujeitos. Essa visão diz respeito a um futuro possível e desejável, expresso também conforme a visão de mundo, imaginários e crenças, com base nas ações do presente e do passado, dado que "o futuro é o fruto da vontade, sendo ela própria conduzida pelos nossos projetos, nossos desejos e nossos sonhos" (GODET; DURANCE, 2008, p. 8).

Para tanto, de início, ponderou-se sobre a sistematização das respostas às perguntas, escolhidas no Ciclo II, por grupos de representantes. Em seguida, selecionaram-se as respostas cuja definição estatística atingiu o valor mínimo de escolha de 60\% (previamente definido). No processo de identificação do ponto de vista da maioria, surgiram "variações nos procedimentos de análise" (MARANHÃO, 2006, p. 3). Adendo 1: houve respostas alternativas consensualmente "nulas" (não escolhidas, com $0 \%$ de votos), com todos os integrantes daquele grupo, demonstrando a conviç̧ão sobre "não estarem de acordo com aquela frase resposta" ou "desconsideraram conjuntamente aquela alternativa" como resposta possível àquele assunto. Sendo assim, compõe a análise do produto final uma resposta com "voto nulo". Adendo 2: analisou-se o resultado cuja

9 Observou-se a média de 3,0 $\pm 1,6$ moradores por domicílio; por isso, a renda média familiar de $R \$ 5.050,00 \pm 4.362,00$ (amplitude: renda familiar mínima $R$ \$ 545,00 e máxima $R$ \$ 30.000,00, ou um salário- mínimo e 55 salários-mínimos, respectivamente). Valor do salário-mínimo em 2011: R\$545,00. Fonte: Guia Trabalhista. Disponível em: <www.guiatrabalhista.com.br/guia/salario_minimo.htm>. Acesso em: 7 fev. 2012. À época, um salário mínimo no Brasil correspondia a aproximadamente US\$230. Fonte: No mercado de câmbio o dólar encerrou 2011 em R\$1,70/US\$". Banco Central do Brasil. Relatório de Inflação, 2011: 21. Disponível em: <http://www.bcb.gov.br/htms/relinf/port/2011/03/ri201103c2p. pdf>. Acesso em: 4 mar. 2013. 
alternativa foi "quase majoritariamente votada", entendendo-se que 57\% "dos opinantes" do grupo da SMS tem "convicção acerca do assunto". ${ }^{10}$

Para apresentar a análise dos resultados, recupere-se aqui que, dos 109 sujeitos participantes da primeira fase, 68 (62,4\%) participaram do Ciclo I da segunda fase e que destes, 51 (ou 75,0\% dos 68) opinaram no Ciclo II final. Representam eles os grupos que definiram o produto final da abordagem prospectiva, proporcionalmente distribuídos em grupos: de representantes dos idosos no CMI (13 ou 72,2\%), de representantes da SMS no CMS (14 ou $70,0 \%$ ) e de usuários (22 ou 73,3\%).

A temática “Quem cuidará de nós em 2030?", como dito antes, tem como principal objetivo verificar o consenso de opiniões de representantes da SMS, dos usuários no CMS e de representantes dos idosos no CMI, a fim de fornecer visões prospectivas no campo da saúde do idoso para 2030. Dados presentes nas tabelas 1-3 demonstram a probabilidade do futuro para a saúde em 2030, relativas às temáticas das questões do formulário: (1) serviços e ações considerados essenciais para atingir um atendimento eficiente e bom à pessoa idosa; (2) profissionais considerados capacitados para desenvolver os serviços e as ações na atenção à saúde do idoso; e (3) como o idoso como gostaria de ser cuidado.

O cenário, cujo tratamento antecede a análise dos resultados, é a consideração de que, em 2030, o perfil médio etário dos representantes dos Conselhos será de $71,7 \pm 12,1$ anos de idade (amplitude: idade mínima de 47 e máxima de 96 anos), lembrando que, em 2011, esse perfil era de 52,7 $\pm 12,1$ anos (amplitude: idade mínima de 28 e máxima de 77 anos).

A velhice pode ser estudada como categoria socialmente produzida. Há, assim, distinção entre fato universal e natural - o ciclo biológico do ser humano e de boa parte das espécies vivas, o que envolve nascimento, crescimento, morte - e um fato subjetivo e sociohistórico, tributo à variabilidade das formas, sob as quais é concebido e vivido o envelhecimento (DEBERT, 1994). Ainda, a respeito da heterogeneidade e da vicissitude do processo de envelhecimento e da longevidade humana, é possível ponderar, tendo como alusão o clássico $A$ Velhice, de Simone de Beauvoir, que:

10 O entendimento aqui se apoia na análise da sistematização dos resultados dos Ciclos I e II, quando se constatou que, no Ciclo I do Delphi, o tema em questão recebeu 83,3\% dos votos do grupo da SMS, sendo este o único que quase atingiu a igualdade de opiniões na resposta alternativa no Ciclo II. 
[...] é um fenômeno biológico [...], acarreta consequências biológicas [...]. [e] tem uma dimensão existencial [...] [que] modifica a relação do indivíduo com o tempo [...], com o mundo e com a própria história [...]. O que torna [esta] questão complexa é a estreita interdependência desses diferentes pontos [...]. Sabe-se, hoje em dia, que é abstrato considerar em separado os dados fisiológicos e os fatos psicológicos: eles se impõem mutuamente... na velhice, essa relação é particularmente evidente: [...] é, por excelência, o domínio do psicossomático. Entretanto, o que chamamos de vida psíquica de um indivíduo só se pode compreender à luz de sua situação existencial; esta última tem, também, repercussões em seu organismo [...]. [Além disso] se a velhice, enquanto destino biológico, é uma realidade que transcende a história, não é menos verdade que este destino é vivido de maneira variável segundo o contexto social [...]. Enfim, é no movimento indefinido desta circularidade que é preciso apreendê-la. (BEAUVOIR, 1990, p. 15-16).

A identidade configurada pelo envelhecer qualifica os idosos em categoria social que parece estar permanentemente em luta para conservar seu lugar, papel e importância na sociedade. A luta concorre para definir parte das alterações biológicas e/ou psicológicas próprias do processo de envelhecimento que, por conseguinte, afetam e são afetadas pelo contexto sociocultural, com ecos na trajetória e qualidade de vida da população idosa, que continua a envelhecer (MERCADANTE, 1997). Um dos componentes mais importantes, do envelhecimento pode ser a atitude dos próprios idosos que, crescentemente, têm representatividade maior em um futuro e possível contexto social mais cuidadoso, assim como pode não ser. Apresenta-se mais uma interpretação social e cultural, entre outras que poderão surgir, para aproximar atores, conselheiros, e objeto: o cuidado.

Serviços e ações: quando perguntados "a respeito dos serviços e ações considerados necessários para atingir um atendimento eficiente e bom à pessoa idosa em 2030", os grupos não chegaram a uma igualdade de opiniões, optando por respostas alternativas, embora o grupo de representantes da SMS no CMS, unanimemente, não tenha escolhido uma das alternativas.

Em uma interpretação no sentido negativo entendeu-se que, no julgamento do grupo, o "não" deveria vir a ser instituído: "Um hospital de retaguarda para o idoso se recuperar e voltar para casa com independência e autonomia", para que o município atingisse em $2030 \mathrm{um}$ atendimento eficiente e bom ao idoso. Historicamente, até 1930 a área da Gerontologia era restrita a teorias. 
À época, encontrou-se um "divisor de águas": os trabalhos de reabilitação para idosos hospitalizados, delineando os primórdios da avaliação interdisciplinar e multidimensional do idoso e dos planos individuais de reabilitação (FREITAS; PY, 2006). Essa é a concepção dos hospitais de retaguarda adotada nos programas de atendimento hospitalar prolongado no SUS.

Atualmente, é objetivo central da reabilitação manter na comunidade o maior número possível de idosos, vivendo integrada e ativamente, com o mais alto nível de autonomia, pelo maior tempo alcançável; e reconhecendo que a continuidade dos "cuidados prolongados em unidade hospitalar" deve estar inserida no sistema de referência e contrarreferência, que protagoniza os princípios da complementaridade e da integralidade da assistência do SUS. O sistema consiste no direito que as pessoas têm de serem atendidas em suas necessidades em diversos níveis de complexidade e é dever do Estado oferecer serviços de saúde específicos para tais cidadãos. Em linhas gerais, o SUS deve atender demandas em variados níveis de complexidade, por meio de ações de promoção, prevenção, recuperação e reabilitação, dando continuidade ao cuidado com a estruturação de um sistema de referência e contrarreferência (DIAS, 2012). A portaria 2.809/12 dispõe:

\begin{abstract}
Art. $5^{\circ}$ - Os Cuidados Prolongados têm como objetivo geral a recuperação clínica e funcional, a avaliação e a reabilitação integral e intensiva da pessoa com perda transitória ou permanente de autonomia potencialmente recuperável, de forma parcial ou total, e que não necessite de cuidados hospitalares em estágio agudo. Parágrafo único. São considerados usuários em situação de perda de autonomia aqueles com limitações físicas, funcionais, neurológicas e/ou motoras, restritos ao leito, ou em qualquer condição clínica que indique a necessidade de cuidados prolongados em unidade hospitalar. (BRASIL, 2012, p. 1).
\end{abstract}

Reiteram-se os preceitos da PNSI (BRASIL, 1999) ao assumir que o principal problema a atingir o idoso, como consequência da evolução de condições crônicas e de sua trajetória de vida, é a perda da capacidade funcional. Enfatize-se, ainda, que a saúde fragilizada do idoso gera, em virtude de intervenções onerosas, acompanhamento constante, cuidados permanentes, medicação contínua e exames periódicos, maior exigência de procedimentos médicos, serviços públicos de saúde e internações hospitalares. A internação do idoso, por vezes, é de tempo prolongado, devido à lentidão na recuperação, acarretando complicações adversas relacionadas à imobilidade e à infecção hospitalar. 
Tabela 1 - Em 2030... Distribuição proporcional de resposta prospectiva não escolhida sobre serviços e ações de saúde, segundo grupo de representantes da SMS no CMS. Ciclo II. Método Delphi. RMSP. 2012. $(n=14)$.

\section{Formulário Delphi II}

Grupo de representantes da SMS no CMS

16. Em 2030, que serviços e ações o(a) Sr(a) considera necessários para atingir um atendimento eficiente e bom à pessoa idosa? O que falta hoje?

\begin{tabular}{|c|c|c|}
\hline $\begin{array}{l}\text { Perguntas e respostas } \\
\text { Produto final }\end{array}$ & $N$ & $\%$ \\
\hline $\begin{array}{l}\text { Um hospital de retaguarda para o idoso se recuperar e voltar } \\
\text { para casa com independência e autonomia. }\end{array}$ & Nenhum & ०\% \\
\hline
\end{tabular}

Fonte: Pesquisa Quem cuidará de nós em 2030?

Durante a internação, o idoso fica isolado, imobilizado ou exposto a contatos, por vezes, superficiais e transitórios com profissionais da saúde, que raramente oferecem atendimento diferenciado e orientações claras. Após a alta hospitalar, na maioria das vezes ele volta à família, com necessidades relacionadas à imobilização no período hospitalar, e não com a causa da admissão no hospital, necessitando de ajuda para realizar cuidados pessoais e locomover-se. Problemas com o sono, incontinência urinária e/ou fecal, entre outros, são aspectos comportamentais ou funcionais vistos em proporção significativa de idosos, no período de internação e pós-alta. Como lidar com isso? Os programas de saúde da família, em sua maioria, limitam-se a utilizar os serviços ambulatoriais especializados. Onde estão os hospitais de retaguarda (de apoio), que servem para materializar, inclusive, as relações ditas de referência e contrarreferência? ${ }^{11}$

11 Dois comentários adicionais, coletados em arenas específicas (privada e pública), dedicadas ao cumprimento (ou não) do exercício daquela política. No primeiro, o hospital de retaguarda como investimento inovador. No segundo, o mesmo equipamento tratado como "arranjo menos importante" - proforma. Para o setor privado: "O hospital de retaguarda possui o diferencial de reunir num ambiente amplo, aconchegante, arborizado, com atividades de recreação e horário de visitas ampliado, todo o suporte de uma estrutura hospitalar e de uma completa equipe multidisciplinar (...) onde o paciente pode continuar seu processo de reabilitação sentindo-se como se estivesse em sua própria casa". Disponível em: <www.recantosaocamilo.com.br/granja/hospital.html>. Acesso em: 20 fev. 2014. No setor público, encontrou-se o seguinte relato do Grupo de Trabalho de Saúde do Consórcio Intermunicipal do Grande ABC: "O Consórcio vê no equipamento uma alternativa de desafogar leitos de prontos-socorros da região, uma vez que o conceito de retaguarda foca no atendimento de pacientes que necessitam de tratamentos prolongados..." Discussão que alcançou o Legislativo são-caetanense, e um vereador defendeu o modelo de parceria público-privada para recuperar o "cadáver sepulto" em referência ao hospital. Fonte: "São Caetano visa sediar hospital de retaguarda para a região". 8 de setembro de 2013. Diário do Grande ABC. Disponível em: <https://www.dgabc.com.br/Noticia/480930/s-caetano-visa-sediar-hospital-de-retaguarda-para-a-regiao?referencia=navegacao-lateral-detalhe-noticia $>$. Acesso em: 20 fev. 2014. 
Profissionais: outro achado que chamou a atenção, ao se analisar o produto final das questões prospectivas, foi que, dentre elas, os representantes dos três grupos, até o término do Ciclo II, não tinham chegado a um consenso sobre os "profissionais" que consideravam "capacitados para desenvolver serviços e ações na atenção à saúde do idoso em 2030".

Ao longo desta análise, verificou-se que o grupo de representantes da SMS se aproximou estatisticamente de um consenso. Guardados os cuidados indispensáveis, entendeu-se que os opinantes desse grupo estavam "convictos" a respeito da resposta alternativa: "Todos os profissionais da rede pública (saúde, esporte e lazer, entre outros) precisariam ser capacitados". O grupo pareceu convencido, pois com seus vários tipos de lentes, "fotografou" os profissionais, revelando imagem que não vai além de luzes, sombras e cores que a aparência, por vezes, deixa surgir. Como os que fotografaram fazem parte da perspectiva adotada, prevaleceu, na imagem, a contundência dos sinais de desgaste de toda a rede pública.

No campo da saúde, são essenciais, portanto, programas de educação permanente, humanização, valorização, formação e treinamento de profissionais da rede. Trata-se de desenvolver e potencializar habilidades para aprimorar a própria prática, os serviços e ações, com os quais o servidor lida no dia a dia do trabalho com o público usuário. Trabalhadores e gestores da saúde precisam ser capazes de refletir sobre crises e mudanças na economia, cultura e política daquela localidade. Eles lidam na rede pública com uma complexidade que requer visão mais estratégica, cooperativa, participativa e solidária para operar na fronteira tênue entre técnica e política, desenvolvendo ações voltadas aos problemas locais; um trabalho de maior relevo, quanto mais colaborar para romper categoricamente o hiato entre realidade local e cumprimento da política, além de potencializar o saber local e neutralizar a execução técnica e compreender que as soluções buscadas dependem de um devir coletivo complexo (NOGUEIRA, 1998).

É importante considerar as especificidades da cultura nacional, na qual o desenho institucional da rede pública aumentou o isolamento dos que decidem, prevalecendo, por vezes, a crença de que o "insulamento burocrático" pode ser controlado pela inserção da sociedade civil na esfera pública (DINIZ, 2000). 
Em linhas gerais, os recursos humanos da rede pública se direcionam para dois pontos dicotômicos: no primeiro, situa-se o "escalão superior," caracterizado pela meritocracia e profissionalização, voltado a carreiras diplomáticas ou à área de planejamento econômico. O segundo, dos "escalões inferiores", em geral de profissionais que se engajam nos serviços sociais, muitas vezes privilegiados pelo critério clientelista de recrutamento por indicação (MARTINS, 1997).

Entende-se, então, que surgiram, na rede pública do País, duas categorias de profissionais: o ineficiente e mal pago, que presta serviços públicos, e o executivo, impregnado da cultura gerencial. $\mathrm{O}$ executivo protagoniza, basicamente, duas "cenas" no contexto político nacional: atua nas "ilhas de excelência" ou estabelece relações com o setor privado, criando redes de corrupções e privilégios. De modo geral, os cidadãos brasileiros sempre tiveram contato mais estreito com a ineficiência dos "escalões inferiores" e com escândalos de corrupção dos "altos escalões" (MARTINS, 1997). Quanto ao "baixo escalão", a medida corretiva recomendada para melhorar a imagem dos prestadores de serviços são os programas da Política de Humanização no SUS (HumanizaSUS), a partir de 2003. Fenômenos genericamente elencados como desumanização, cuja origem não está no fato em si, tomam dimensão concreta e real, expressam mais que falhas éticas individuais (de um ou outro trabalhador/gestor); envolvem certo modo de se conceber e organizar o trabalho em saúde (BRASIL, 2004; 2010):

\begin{abstract}
A PNH define a humanização como um modo de fazer inclusão, como uma prática social ampliadora dos vínculos de solidariedade e corresponsabilidade, uma prática que se estende seguindo o Método da Tríplice Inclusão. Assim, a feitura da humanização se realiza pela inclusão, nos espaços da gestão, do cuidado e da formação, de sujeitos e coletivos, bem como dos analisadores (as perturbações) que estas inclusões produzem. Em outras palavras: humanização é inclusão. (BRASIL, 2010, p. 7).w
\end{abstract}

Trata-se, reconhecidamente, de uma política de formação da responsabilidade pública, processo lento que envolve julgamento moral, valores e aprendizado cotidiano de saber fazer. 
Tabela 2 - Em 2030... Distribuição proporcional da visão prospectiva sobre os profissionais capacitados, segundo grupos de representantes dos idosos no CMI, da SMS e dos usuários no CMS. Ciclo II. Método Delphi. RMSP. 2012.

Formulário Delphi II

Grupo de representantes

17. A partir da sua experiência, quais profissionais o(a) $\operatorname{Sr}(a)$ considera capacitados para desenvolver serviços e ações na atenção à saúde do idoso em 2030 ?

\begin{tabular}{l|c|c|c|c|c|c}
\hline Perguntas e respostas & \multicolumn{2}{|c|}{ dos idosos } & \multicolumn{2}{|c|}{ da SMS } & \multicolumn{2}{|c|}{ dos usuários } \\
\hline Produto final & $\mathrm{N}$ & $\%$ & $\mathrm{~N}$ & $\%$ & $\mathrm{~N}$ & $\%$ \\
\hline $\begin{array}{l}\text { Todos os profissionais da rede pública (saúde, } \\
\begin{array}{l}\text { esporte e lazer, entre outros) precisariam ser } \\
\text { capacitados. }\end{array}\end{array}$ & 5 & $38 \%$ & 8 & $57 \%$ & 9 & $41 \%$ \\
\hline
\end{tabular}

Fonte: Pesquisa Quem cuidará de nós em 2030?

Embora a Legislação Brasileira, relativa aos cuidados da população idosa, seja bem avançada, as ações e serviços de saúde na rede pública ainda não são satisfatórios.

Como gostaria de ser cuidado: quando questionados sobre "como gostaria de ser cuidado em 2030?", 62\% dos representantes do grupo dos idosos e 64\% dos representantes do grupo da SMS escolheram: "Que minha família e profissionais capacitados cuidassem de mim, na comunidade, convivendo com diferentes gerações". Representantes desses grupos admitem a necessidade de cuidados na velhice, a preferência por familiares/profissionais capacitados e por permanecer no lócus onde residem. Mas, quem serão os velhos em 2030? Todos necessitarão de cuidados?

Destaque-se que o processo de transição demográfica é reflexo direto das tendências de redução das taxas de fecundidade, mortalidade e aumento da expectativa de vida ao nascer, evidenciando que os velhos em 2030 estarão morando sozinhos, ou talvez em companhia de pouquíssimos entes familiares, por vezes idosos. Em proporção mais representativa, relativamente ao total da população, aqueles velhos serão sobreviventes da própria velhice 
por manterem-se vivos para além dos 60 anos, quando passam a pertencer ao segmento idoso. A velhice abrigará um excedente de mulheres e se transformará em período etário bastante diversificado e representativo, especialmente nos extremos, nos quais as faixas etárias se polarizam: de um lado, os de 60 anos, e do outro, o segmento com maior crescimento, os de 80, 90 e centenários. A heterogeneidade explicitará e diferenciará o modo e a condição de vida dos velhos, quando, ao mesmo tempo, homens e mulheres estarão ativos, com autonomia para desenvolver as tarefas do dia a dia e continuar no mercado de trabalho, e/ou perderão a autonomia em decorrência do devir e necessitarão de cuidados, tal qual Born (2011) recomenda:

Por isso, o atendimento não asilar necessita de programas com pessoal preparado, espaço e equipamentos adequados. Nesse sentido, quinze anos após a regulamentação da Política Nacional do Idoso, pelo Decreto n.' 1948/96, são ainda insuficientes as ações do governo e da sociedade civil para tornar realidade aquela diretriz, por meio de equipamentos sociais e programas como centro de convivência, centro de cuidados diurnos, casalar e atendimento domiciliar. (lbid., p. 9-11).

Dentre as respostas prospectivas acerca de como gostariam de ser cuidados, emergiu alternativa com "voto nulo" ( $0 \%$ de escolha). Ao preterirem a alternativa "com atendimento humanizado, tal como é aqui no município hoje", todos os representantes do grupo da SMS abriram espaço, primeiramente, para uma visão negativa dos serviços existentes hoje e, em segundo lugar, para as possíveis dificuldades a serem enfrentadas por aqueles velhos a serem assistidos em 2030. São dificuldades que se substanciarão, em um futuro próximo, pela redução da ação do núcleo familiar nos cuidados aos idosos, tributária ao possível despreparo urbano para proporcionar serviços que garantam o bem-estar desejado e o acesso aos direitos, desde o atendimento no local onde residem, por profissionais capacitados no campo da saúde do idoso, até todas as ações e serviços de distintos órgãos da rede pública e privada. 
Tabela 3 - Em 2030... Distribuição proporcional de respostas prospectivas e consensuais sobre como gostaria de ser cuidado, segundo grupos de representantes dos idosos no CMl, da SMS e dos usuários no CMS. Ciclo II. Método Delphi. RMSP. 2012.

Formulário Delphi II

Grupo de representantes

18. Como o(a) Sr(a) gostaria de ser cuidado (a) em 2030 ?

\begin{tabular}{l|c|c|c|c|c|c}
\hline Perguntas e respostas & \multicolumn{2}{|c|}{ dos idosos } & \multicolumn{2}{|c|}{ da SMS } & \multicolumn{2}{c}{ dos usuários } \\
\hline Produto final & $N$ & $\%$ & $N$ & $\%$ & $N$ & $\%$ \\
\hline $\begin{array}{l}\text { Que minha família e profissionais capaci- } \\
\text { tados cuidassem de mim, na comunidade } \\
\text { convivendo com diferentes gerações. }\end{array}$ & 8 & $62 \%$ & 9 & $64 \%$ & & \\
\hline $\begin{array}{l}\text { Com respeito, simplicidade, igualdade e } \\
\text { liberdade. }\end{array}$ & & & & & 14 & $64 \%$ \\
\hline $\begin{array}{l}\text { Com atendimento humanizado, tal como } \\
\text { é aqui no município hoje. }\end{array}$ & nenhum & $0 \%$ & nenhum & $0 \%$ & nenhum & $0 \%$ \\
\hline
\end{tabular}

Fonte: Pesquisa Quem cuidará de nós em 2030?

O grupo dos representantes dos usuários (64\%) gostaria de ser cuidado "Com respeito, simplicidade, igualdade e liberdade", resposta que expressa o "cuidado" localizado em todas as situações e ações; "representa uma atitude de ocupação, preocupação, de responsabilização e de envolvimento afetivo com o outro" (BOFF, 1999, p. 9). Ao se refletir sobre quais as ações de cuidar de si e do outro que se pleiteia para a própria velhice, defronta-se com um aumento da demanda por cuidados exigidos pela velhice. Neste ponto, deve-se lembrar de que o cuidado só surge quando alguém tem importância para si e/ou para o próximo, que se dedique a participar do próprio fardo ou de outrem, de seus desejos, sofrimentos, enfim, de sua vida, processo indiciador de que o ser humano não vive sem cuidado, "essência da vida humana" (BOFF, 1999, p. 37).

Tomando este estudo como referência, a provisão de cuidados para a população idosa é obrigação do Estado, das famílias ou do mercado privado? A perspectiva é de que a responsabilidade seja compartilhada entre os três atores, implicado o voluntariado (CAMARANO, 2012). Vislumbra-se, para garantir uma assistência mais qualificada aos idosos, que os diferentes atores promovam ações que (1) preconizem serviços de cuidados para além da filantropia e do asilo; (2) ampliem o sistema formal de apoio, por meio da identificação e fortalecimento das redes formadas por centros-dia, hospitais de retaguarda, centros de lazer, instituição de longa permanência e cuidado domiciliar, entre outros. 
Na análise quantitativa, com referencial teórico de Geertz (1973; 1997), buscou-se capturar no discurso dos depoentes interpretações subjetivas, negando a naturalização de explicações aparentes, na tentativa de revelar a essência do pensamento e/ou sentimento do sujeito diante da problemática em foco.

Estratégias para analisar os resultados também foram se configurando alvo longo do processo de aproximação e delimitação do trabalho de campo durante os procedimentos metodológicos deste estudo. São exemplares: (I) as reflexões que levaram a uma perspectiva interdisciplinar da análise prospectiva, qualitativamente sustentada na infraestrutura e na dinâmica político-administrativa dos equipamentos comunitários (os Conselhos Municipais de Saúde e do Idoso); e (II) as informações registradas em diários de campo que contribuíram subjacentemente às análises feitas, ao possibilitar o resgate do contexto sociocultural das respostas, favorecendo a identificação de cuidados específicos à velhice, imprescindíveis para a compreensão da relação dinâmica e interdependente entre sujeito-objeto, ou seja, do vínculo entre mundo real objetivo e subjetividade do sujeito. O referencial teórico e a perspectiva de análise interdisciplinar (tributários a avanços científico-tecnológicos) permitiram a interpretação sociocultural dos resultados, permitindo captar subjetividades e a essência do pensamento e/ou sentimento do discurso dos depoentes, diante da problemática estudada: a velhice e a atenção à saúde. As opiniões mostram a necessidade de melhorar a infraestrutura e a dinâmica político-administrativa dos equipamentos comunitários (neste caso, os Conselhos Municipais de Saúde e do Idoso), pró-fortalecimento da rede de apoio e implantação da Atenção à Saúde dos Idosos em 2030. Os sujeitos prospectam os cuidados que desejam para a própria velhice, lembrando a negligência aos cuidados específicos trazidos pelo processo de envelhecimento e velhice; no atual contexto sociocultural, fazem-se referência: indireta de cuidados a um idoso genérico, merecedor de consideração pela contribuição social dada ao longo da vida; e aos cuidadores familiares, destacados como os melhores.

Frise-se a relevância do tema "Quem cuidará de nós em 2030?" ao enfocar o envelhecimento populacional e os serviços de saúde para idosos hoje e em um futuro próximo. Acima de tudo: a problemática de cuidados, as demandas de atendimentos e as dificuldades ao acesso devem ser mais bem planejadas no sistema público de saúde brasileiro. 


\section{abstract}

This study was guided by the question: "Who will take care of us in 2030?". Developed in São Paulo Metropolitan Area and anchored in the Brazilian Public Policy for Elderly Healthcare, the study investigated the opinions of representatives of the São Paulo Health and Elderly Boards regarding this question. Results of the investigation: (i) There is no need to create a "backup hospital for elderly patients to recover and return home with independence and autonomy"; (ii) Necessary to train "all healthcare staff in the public sector"; (iii) Need to recognize the increased demand for elderly care. In the near future, these Boards may become a powerful tool of social participation and empowerment in the public sphere so that policies can be developed to best meet the demands of old age.

keywords

Prospective Method. Brazilian Healthcare System. Elderly People.

referências

BEAUVOIR, Simone de. A velhice. Rio de Janeiro: Nova Fronteira, 1990.

BOFF, Leonardo. Saber cuidar: ética do humano - compaixão pela terra. Petrópolis: Vozes, 1999.

BORN, Tomiko. Quem vai cuidar de mim quando eu ficar velha? Dez anos depois: considerações sobre família, assistência médica, lugar para morar, (im)previdência social e outras coisas mais. Revista Portal de Divulgação, São Paulo, v. 17, n. 1, p. 4-15, dez. 2011. Disponível em: <http://www.portaldoenvelhecimento.org.br/revista-nova/index. php/revistaportal/article/viewFile/211/211>. Acesso: 21 fev. 2012.

BRASIL. Portaria n. ${ }^{\circ} 2.809$, de 07 de dezembro de 2012. Estabelece a organização dos Cuidados Prolongados para retaguarda à Rede de Atenção às Urgências e Emergências (RUE) e às demais Redes Temáticas de Atenção à Saúde no âmbito do Sistema Único de Saúde (SUS). Ministério da Saúde, Gabinete do Ministro, Brasília, DF, 2012. Disponível em: <http://bvsms.saude.gov.br/bvs/saudelegis/gm/2012/prt2809_07_12_2012. html>. Acesso em: 21 fev. 2014.

Política Nacional de Humanização (PNH). Formação e intervenção. Ministério da Saúde, Secretaria de Atenção à Saúde. Brasília: Ministério da Saúde, 2010.

. Política Nacional de Saúde da Pessoa Idosa (PNSPI). Brasília: Ministério da Saúde, 2006. Disponível em: <http://bvsms.saude.gov.br/bvs/folder/politica_nacional_ pessoa_idosa_2009.pdf>. Acesso em: 20 out. 2016. 
BRASIL. HumanizaSUS: Política Nacional de Humanização: documento base para gestores e trabalhadores do SUS. Brasília: Ministério da Saúde, 2004.

União, Brasilia, DF, out. 2003

Guia do conselheiro: curso de capacitação de conselheiros estaduais e municipais de saúde. Brasília: Ministério da Saúde, 2002.

Portaria n 1.395, de 10 de dezembro de 1999. Política Nacional de Saúde do Idoso. Brasília: Ministério da Saúde, 1999. Disponível em: <http://www.ufrgs. br/3idade/?page_id=117>. Acesso em: 20 out 2016.

Constituição (1988)

CAMARANO, Ana Amélia. Cuidados de longa duração para a população idosa: um novo risco a ser assumido? In: HIRATA, Helena; GUIMARÃES, Nadya Araujo (Org.). Cuidados e cuidadores: As várias faces do trabalho do care. São Paulo: Atlas, 2012.

CONCONE, Maria Helena Villas Bôas. Cura e visão de mundo. Revista Kairós, São Paulo, v. 6, n. 2, p. 45-59, dez. 2003.

DANTAS, Fernando. Brasil envelhece antes de enriquecer. O Estado de S. Paulo, São Paulo, 7 abr. 2011. Caderno Economia. Disponivel em: <http://economia.estadao.com.br/ noticias/geral,brasil-envelhece-antes-de-enriquecer,702873>. Acesso em: 20 out. 2016

DEBERT, Guita Grin. Pressupostos da reflexão antropológica sobre a velhice. In: (Org.). Antropologia e velhice: textos didáticos. Campinas: IFCH/UNICAMP, 1994

DIAS, Valdecir Ávila. Referência e contra-referência: um importante sistema para a complementaridade da integralidade da assistência. 2012. 38 f. Trabalho de Conclusão de Curso (Especialização em Saúde Pública) - Departamento de Saúde Pública, Universidade Federal de Santa Catarina, Florianópolis, 2012. Disponível em: <http:// spb.ufsc.br/files/2012/09/TCC-Valdecir-Avila-Dias-.pdf>. Acesso em: 21 fev. 2014.

DINIZ, Eli. Globalização, reformas econômicas e elites empresariais. Rio de Janeiro: FGV, 2000.

FIOCRUZ. Saúde no Brasil em 2030: diretrizes para a prospecção estratégica do sistema de saúde brasileiro. Rio de Janeiro: Fiocruz, 2012

FREITAS, Elizabete Viana de; PY, Ligia (Ed.). Tratado de Geriatria e Gerontologia. Rio de Janeiro: Guanabara Koogan, 2006

GEERTZ, Clifford James. O saber local: novos ensaios em antropologia interpretativa. Rio de Janeiro: Vozes, 1997

A interpretação das culturas. Rio de Janeiro: LTC, 1973.

GIOVINAZZO, Renata Alves. Modelo de Aplicação da Metodologia Delphi pela Internet - Vantagens e Ressalvas. Administração On Line, São Paulo, v. 2, n. 2, abr.-maio-jun. 2001. Disponível em: <http://www.fecap.br/adm_online/art22/renata.htm>. Acesso em: 21 fev. 2014

GODET, Michel; DURANCE, Philippe. A prospectiva estratégica: para as empresas e os territórios. Paris: Dunod, 2008.

HELMER, Olaf. Problems in futures research: Delphi and casual cross-impact analysis. Futures, Amsterdam, v. 9, n. 1, p. 17-31, Feb. 1977.

INSTITUTO BRASILEIRO DE GEOGRAFIA E ESTATÍSTICA (IBGE). Síntese de Indicadores Sociais: Uma Análise das Condições de Vida da População Brasileira. Est. e Pesq. Inf. Demográfica e Socioeconômica, n. 27. Rio de Janeiro: Ministério do Planejamento, Orçamento e Gestão, 2010. 
INSTITUTO DE PESQUISA ECONÔMICA APLICADA (IPEA). O Conselho Nacional de Saúde na Visão de seus Conselheiros: Relatório de Pesquisa. Projeto Conselhos Nacionais: perfil e atuação dos conselheiros. Brasília: IPEA, 2012.

MARANHÃO, Eduardo Severiano Ponce. Método Delphi. Apresentação para o Curso de avaliação de serviços e programas de saúde (strictu sensu). Departamento de Epidemiologia e Métodos Quantitativos em Saúde, ENSP/Fiocruz, 2006. Disponível em: <www5.ensp.fiocruz.br/biblioteca/dados/txt_533410787.ppt>. Acesso em: 14 abr. 2012

MARTINELLI, Maria Lúcia (Org.). Pesquisa qualitativa: um instigante desafio. São Paulo: Veras, 1999.

MARTINS, Luciano. Reforma da administração pública e cultura política no Brasil: uma visão geral. Cadernos ENAP, n.8, Brasília: ENAP, 1997.

MERCADANTE, Elizabete Frohlich. A construção da identidade e subjetividade do idoso. 1997.Tese (Doutorado em Ciências Sociais) - Pontifícia Universidade Católica de São Paulo, São Paulo, 1997.

NOGUEIRA, Marco Aurélio. As possibilidades da política: ideias para a reforma democrática do Estado. São Paulo: Paz e Terra, 1998.

NÚMERO recorde de jovens e idosos é desafio para países, diz ONU. BBC Brasil. 26 out. 2011. Disponível em: http://www.bbc.com/portuguese/noticias/2011/10/111025_ onu_populacao_jovens_mdb.shtml. Acesso em: 30 jan. 2016.

ORGANIZAÇÃO MUNDIAL DE SAÚDE (OMS). Envelhecimento Ativo: uma política de saúde. Tradução Susana Gontijo. Brasilia: Organização Pan Americana de Saúde, 2005.

PINCHIARO, Gustavo. São Caetano visa sediar hospital de retaguarda para a região. Diário do Grande ABC. 8 set. 2013. Disponível em: http://www.dgabc.com.br/ Noticia/480930/s-caetano-visa-sediar-hospital-de-retaguarda-para-a-regiao. Acesso em: 30 jan. 2016.

RECANTO SÃO CAMILO, O Hospital Retaguarda. Disponível em: http://www.recantosaocamilo.com.br/granja/hospital.html. Acesso em: 30 jan. 2016.

WRIGHT, James Terence Coulter; GIOVINAZZO, Renata Alves. Delphi - Uma ferramenta de apoio ao planejamento prospectivo. Caderno de Pesquisas em Administração, SãoPaulo, v. 1, n. 12, p. 54-64, 2. tri. 2000. 